\title{
Psicologia na atenção primária à saúde: reflexões e implicações práticas ${ }^{1}$
}

\author{
Juliane Fernandes Simões de Mattos Andrade \\ Universidade Federal de São Carlos, São Carlos-SP, Brasil \\ Cristiane Paulin Simon ${ }^{2}$ \\ Universidade Federal do Triângulo Mineiro, Uberaba-MG, Brasil
}

\begin{abstract}
Resumo: A inserção da Psicologia na atenção primária à saúde tem sido alvo de discussões com propostas de mudanças, nas últimas duas décadas. Esta pesquisa teve como objetivo caracterizar as práticas psicológicas desenvolvidas neste contexto em Ribeirão Preto-SP e identificar se as propostas de atuação nesta área foram incorporadas. Cinco psicólogas que trabalhavam neste contexto foram entrevistadas. Os dados obtidos foram analisados sob a perspectiva da Psicologia Social da Saúde. Os resultados mostraram que as profissionais não tiveram formação específica em saúde pública, seja na graduação ou na pós-graduação. As práticas psicológicas se restringiram aos atendimentos em nível secundário dirigidos às crianças e aos adolescentes com problemas emocionais e comportamentais. Consideramos premente a incorporação de conteúdos de saúde pública nos currículos de graduação e a efetivação da educação permanente nos serviços, como estratégia de reorganização dos serviços de psicologia.
\end{abstract}

Palavras-chave: serviços de saúde pública, psicologia da saúde, psicólogos.

\section{Psychology in primary health care: reflexions and practical issues}

\begin{abstract}
The inclusion of Psychology in the primary health care has been a subject under discussion with proposals of change in the recent decades. This study aimed to characterize psychological practices in the primary health care in Ribeirão Preto-SP, Brazil and verify whether proposals to change practices were incorporated. Five psychologists working in this context were interviewed. Collected data were analyzed through the Social Health Psychology perspective. Results revealed that the professionals did not have specific undergraduate or graduate education in public health. The psychological practices were restricted to consultations at a secondary care level focused on children and adolescents with emotional and behavioral problems. We consider mandatory the inclusion of public health topics in undergraduate programs as well as the promotion of continuous education as a strategy to reorganize psychological services.
\end{abstract}

Keywords: public health services, health care psychology, psychologists.

\section{Psicología en la atención primaria de salud: reflexiones e implicaciones prácticas}

\begin{abstract}
Resumen: La inclusión de la Psicología en la atención primaria de salud ha sido objeto de debates y propuestas de cambios en las últimas dos décadas. Este estudio tuvo el objetivo de caracterizar las prácticas psicológicas desarrolladas en Ribeirão Preto-SP, Brasil e identificar si las medidas de actuación propuestas fueron incorporadas al área de atención primaria. Cinco psicólogas que trabajaban en este contexto fueron entrevistadas. Los datos obtenidos fueron analizados bajo la perspectiva de la Psicología Social de la Salud. Los resultados mostraron que los profesionales no tuvieron formación específica en salud pública, durante los estudios de grado o de postgrado. Las prácticas psicológicas se limitaban a cuidados en el nivel secundario, dirigidos a niños y adolescentes con problemas emocionales y comportamentales. Consideramos urgente incluir contenidos referentes a salud pública en la formación de grado así como la efectiva educación permanente como estrategia de reorganización de la asistencia psicológicas.
\end{abstract}

Palabras clave: servicios de salud publica, psicología de la salud, psicólogos.

No Brasil, a inserção da Psicologia na saúde pública ocorreu em um contexto histórico caracterizado pela crise financeira vivida na década de 1970 que afastou a classe média dos consultórios. Associada a esta condição, havia um clima propício à inclusão de profissionais de outras áreas do conhecimento no campo da saúde coletiva devido à mudança do paradigma em saúde e do movimento da reforma sanitária.

1 O presente artigo é fruto da monografia da primeira autora durante seu curso de graduação em Psicologia na Faculdade de Filosofia, Ciências e Letras de Ribeirão Preto da Universidade de São Paulo. Este texto foi revisado seguindo Acordo Ortográfico da Língua Portuguesa (1990), em vigor a partir de $1^{\circ}$ de janeiro de 2009 .

2 Endereço para correspondência:

Profa. Dra. Cristiane Paulin Simon. Universidade Federal do Triângulo Mineiro. Departamento de Medicina Social. Av. Getúlio Guarita, 130 CEP 38.025-440. Uberaba-MG, Brasil.E-mail: crispaulin@yahoo.com
O processo de mudança do paradigma em saúde destacou-se na década de 1970 pela constatação da fragilidade do modelo biomédico, diante do novo perfil epidemiológico caracterizado não mais pelas doenças infecciosas, mas pelas doenças crônico-degenerativas. Acrescentamos a esta limitação a preocupação dos governos dos países desenvolvidos com os altos gastos com os procedimentos curativos que envolviam alta tecnologia e tornavam-se cada vez mais onerosos aos cofres públicos (Simon, 2003). Para atender a esta nova demanda, discussões e eventos coordenados pela Organização Mundial de Saúde foram realizados, culminando na elaboração de dois importantes documentos que se tornaram marcos conceituais na reorientação dos serviços de saúde e no novo paradigma da saúde pública: a Declaração de Alma-Ata (1978) e a Carta de Ottawa (1986).

A partir da Declaração de Alma-Ata, priorizou-se a aproximação dos serviços de saúde com as necessidades da 
população, sua participação na tomada de decisões e a reorientação dos serviços. A atenção primária à saúde ficou definida, entre outros aspectos, como a porta de entrada da população no sistema nacional de saúde, responsável pela coordenação e integração dos cuidados em saúde. Ela é considerada o nível mais próximo do contexto social e cultural do usuário que possibilita o enfoque nos determinantes de saúde, portanto, tem como foco os indivíduos, as suas famílias e a população, e não a enfermidade. As práticas desenvolvidas são fundamentadas na análise das necessidades e no acompanhamento longitudinal da população, direcionadas para a promoção, manutenção e melhoria da saúde (Starfield, 2002).

A Carta de Ottawa (1986) tornou-se um marco conceitual para o novo paradigma da Saúde Pública, por apresentar um conceito positivo de saúde, enfatizar as ações intersetoriais e definir como pré-requisitos para a saúde: a paz, a educação, a moradia, a alimentação, a renda, um ecossistema estável, justiça social e a equidade.

No Brasil, estas discussões e proposições se fizeram presentes no movimento da reforma sanitária liderado por profissionais de diferentes áreas da saúde, sociedade civil e diversos grupos sociais que lutavam pelo direito universal de assistência à saúde, fundamentada em um modelo explicativo do processo saúde-doença amplo e significativo, em que todas as dimensões do viver a vida fossem contempladas (Mendes, 2006).

A década de 1980 foi marcada tanto pelas discussões políticas como acadêmicas na busca de um modelo de atenção que respondesse às necessidades e aos anseios dos diferentes segmentos da população. A VIII Conferência Nacional de Saúde realizada em 1986 refletiu tal posicionamento e favoreceu o processo de ampliação da diversidade de profissionais no campo da saúde, ao propor uma concepção de saúde como efeito real de uma série de condições coletivas de existência, como direito de cidadania e não como um simples estado biológico abstrato de ausência de patologias, superando, dessa maneira, a concepção medicalizada de saúde (Luz, 1994). Fatores políticos, econômicos, sociais, culturais, ambientais, comportamentais e biológicos foram incorporados como determinantes no processo saúde-doença. A importância da promoção de saúde e da participação comunitária foi ratificada, assim como a necessidade de reorientação dos serviços e de estabelecimento de uma nova política de saúde pública.

A proposta realizada na conferência se concretizou parcialmente em 1988 com a nova Constituição Federal e efetivamente em forma da Lei 8.080 de 1990 que instituiu o Sistema Único de Saúde (SUS), com o propósito de produzir serviços de saúde para o setor público de maneira descentralizada, regionalizada e hierarquizada. Dessa maneira, indicou uma prática que não se limitasse ao combate de doenças e ao modelo biomédico, expandindo a ação dos profissionais de saúde para todos os níveis de atenção (primário, secundário, terciário), ressaltando a importância da prevenção e da promoção de saúde e possibilitando, de maneira mais incisiva, o ingresso de novas categorias no campo da saúde pública.
A prática psicológica no contexto da atenção primária à saúde ocorreu, inicialmente, por meio da transposição do modelo clínico de atuação tradicional. As particularidades deste campo de práticas não receberam a devida atenção do profissional que se posicionou de maneira acrítica, descontextualizada e a-histórica, como bem discutido por Silva (1992).

Mais de vinte anos se passaram desde a aprovação do SUS, e nesse período vários estudos foram realizados sobre a Psicologia na atenção primária, apontando a necessidade de modificação e revisão da formação profissional no nível da graduação e do aperfeiçoamento, e para a adoção de um modelo de atuação mais coerente com a realidade e necessidades da saúde pública no Brasil, principalmente, da população por ela atendida (Conselho Federal de Psicologia, 1988; Silva, 1992; Dimenstein, 1998, 2000).

As novas Diretrizes Curriculares para o curso de Psicologia (Conselho Nacional de Educação, 2004) trouxeram como habilidades e competências gerais do psicólogo a prevenção e promoção de saúde adequadas ao contexto da populaçãoalvo, em níveis individuais e coletivos; ressaltaram a importância da interface entre as diferentes, porém complementares, áreas do conhecimento tais como aquelas que estudam os fenômenos biológicos e sociais; colocaram a compreensão crítica dos fenômenos sociais, econômicos, culturais e políticos como um dos compromissos do psicólogo; e destacaram a necessidade do profissional ser capaz de adequar seu referencial teórico à demanda da população-alvo.

As diretrizes reavivaram as discussões sobre a prática psicológica, no contexto da atenção primária à saúde com o aumento do número de publicações sobre o tema. Dimenstein (2003), que tem adotado tal tema como prioridade em seus estudos, retoma neste artigo teórico a necessidade de reformulação dos currículos de graduação, fundamentada em uma perspectiva diferente do que seja a Psicologia, pois do contrário estaremos fadados a pequenas e sutis mudanças de conteúdos, mas não de visão de mundo.

Tal posição é reforçada na discussão apresentada por Soares (2005) que faz uma revisão da literatura na área e aponta para a inserção de psicólogos em equipes de saúde da família e a adoção de abordagens da Psicologia Social e Comunitária como possíveis caminhos a serem assumidos na superação do modelo de atuação.

Oliveira e cols. (2004) e Ronzani e Rodrigues (2006), em estudos realizados com psicólogos das Unidades Básicas de Saúde de Natal-RN e Juiz de Fora-MG, respectivamente, encontraram resultados muito semelhantes no que diz respeito ao predomínio do modelo individualista, biomédico e hegemônico das práticas psicológicas, bem como da psicologização do processo saúde-doença. Para Oliveira e cols. (2004), a referência clínica ainda predomina na formação dos profissionais e se reflete na compreensão tanto para os mesmos como para a população de que psicoterapia é sinônimo de atuação psicológica.

Em outro trabalho, Oliveira e cols. (2005) investigaram como as práticas psicológicas são registradas no SUS e constataram que o Sistema de Informações Ambulatoriais 
(SIA-SUS) reproduz o modelo tradicional da Psicologia com ênfase nas psicoterapias. Sendo assim, o próprio serviço de saúde limita a possibilidade de ampliação das práticas psicológicas na atenção primária. Neste sentido e pautando-se pela preocupação com a formação do psicólogo para atuação na saúde pública, o ano de 2006 foi definido pelo Conselho Federal de Psicologia como o ano da Psicologia e da Saúde Pública. Durante todo o período, foram realizadas discussões, mesas-redondas, debates, palestras, entre outras atividades que culminaram na realização do I Fórum Nacional de Psicologia e Saúde Pública, em Brasília, no final do mesmo ano, e na pesquisa em parceria com a Associação Brasileira para o Ensino de Psicologia (ABEP) (Spink, 2006). Segundo os organizadores, o evento representou uma possibilidade de "acerto de contas" de várias pendências produzidas ao longo da inserção da Psicologia como profissão na área da Saúde, relativas aos aspectos políticos, administrativos e técnicos.

No âmbito governamental, o Ministério da Saúde também tem se aproximado da reflexão a respeito da maneira como se dá a inserção, não só da Psicologia, mas de todos os profissionais de saúde, no contexto da saúde pública. Estabeleceu parcerias com outros órgãos com o objetivo de fomentar pesquisas e vem desenvolvendo estratégias de ação, tais como o Humaniza Sus, o qual, segundo Dimenstein (2006), visa a alcançar uma maior qualificação da atenção e da gestão em saúde. Para a autora, trata-se de uma política nacional que opera transversalmente em todos os níveis do sistema, fugindo da lógica tradicional baseada em programas e que tem, na humanização, o eixo norteador das práticas de atenção e gestão.

Outro incentivo do Governo Federal foi em relação à formação de profissionais de todas as áreas da saúde para atuar na estratégia saúde da família (fundamental para operacionalização da atenção primária à saúde no Brasil), a partir da residência multiprofissional. Clemente e cols. (2008) avaliaram tal experiência na cidade de São Paulo pela ótica da formação de psicólogos e constataram que este tipo de formação em serviço permite o desenvolvimento de práticas interdisciplinares e a experimentação e autonomia nos novos fazeres psicológicos, a partir da concepção mais ampliada do processo saúde-doença. No entanto, estes fazeres são limitados pelos códigos SIA-SUS que, para os autores, se fundamentam em outro paradigma de conhecimento, baseado no modelo hegemônico da Psicologia.

As discussões teóricas têm se intensificado nos últimos anos, e as críticas e necessidades de mudanças foram absorvidas. É evidente também um maior espaço para discussão e reflexão sobre as práticas desenvolvidas e a formação na área. Mas e na prática? Como a Psicologia está inserida atualmente na atenção primária? Essas mudanças na teoria já podem ser sentidas no cotidiano dos serviços ou apenas em programas de formação como, por exemplo, as residências? $\mathrm{Na}$ tentativa de responder a tais questões, realizamos um mapeamento das práticas psicológicas oferecidas nos serviços de atenção primária à saúde de um município do interior do Estado de São Paulo, buscando caracterizá-las e, assim, identificar se as propostas de mudança na atuação do psicólogo nesta área foram incorporadas.

\section{Método}

Desenvolvemos o presente estudo segundo enfoque qualitativo, sob a perspectiva da psicologia crítica da saúde que busca um posicionamento crítico e reflexivo frente às teorias e aos modelos de atuação tradicionais, homogêneos e descontextualizados, fundamentada por uma epistemologia social (Crossley, 2000).

\section{Participantes}

Foram convidados a participar da pesquisa os psicólogos lotados nas Unidades Básicas e Distritais de Saúde do município de Ribeirão Preto-SP, no período de coleta de dados, entre novembro de 2006 e março de 2007. Segundo dados fornecidos pelo Setor de Recursos Humanos da Secretaria da Saúde, em novembro de 2006 eram 25 os psicólogos vinculados a esta secretaria. O serviço de psicologia realizado por esses profissionais estava estruturado no nível secundário de atenção. Os adultos eram atendidos nos serviços especializados de saúde mental - Ambulatório de Saúde Mental, Núcleo de Saúde Mental e Centro de Atenção Psicossocial (CAPs), já as crianças e adolescentes eram atendidos nas Unidades Básicas e Distritais de Saúde. A rede básica de saúde da cidade contava com 25 Unidades Básicas (UBS) e cinco Unidades Distritais de Saúde (UBDS), sendo que apenas nove psicólogos, dos 25 , trabalhavam na atenção primária à saúde. Destes, dois se encontravam afastados e dois não aceitaram participar da pesquisa, resultando em cinco participantes.

\section{Procedimento}

Utilizamos um roteiro semiestruturado para realização das entrevistas as quais foram gravadas, após a assinatura do Termo de Consentimento Livre e Esclarecido, tiveram duração aproximada de uma hora e foram transcritas na íntegra.

O roteiro de entrevista foi elaborado com base nos objetivos da pesquisa e da literatura sobre técnicas de entrevista (Bogdan \& Biklen, 1994; Delgado \& Gutierrez, 1995; Lodi, 1992). Os temas abordados foram: formação profissional; demanda; práticas psicológicas; avaliação do serviço pelos órgãos responsáveis e pelos profissionais. Entretanto, para este trabalho selecionamos os temas formação em saúde pública e práticas psicológicas na atenção primária à saúde.

Realizamos o contato com os possíveis participantes inicialmente via telefone, momento em que apresentamos os objetivos do estudo e convidamos à participação. Diante da aceitação do profissional, marcamos horário e local para a entrevista. Antes do início, fizemos a leitura do Termo de Consentimento Livre e Esclarecido para sua assinatura. Este projeto foi elaborado segundo a Resolução no 196/96 sobre Diretrizes e Normas Regulamentadoras de Pesquisa Envolvendo Seres Humanos (Brasil, 2000), submetido e aprovado pelo Comitê de Ética em Pesquisa da Faculdade de Filosofia, Ciências e Letras de Ribeirão Preto da Universidade de São Paulo. 


\section{Análise de dados}

Para análise dos dados, utilizamos os procedimentos descritos por Minayo (1994) e Valles (1997) para análise de conteúdo temática: leitura flutuante, pré-análise, exploração do material e tratamento dos resultados obtidos e interpretação. Para interpretação, realizamos diversas leituras críticas sobre as práticas psicológicas oferecidas nas Unidades Básicas e Distritais de Saúde, a partir da perspectiva dos profissionais atuantes no serviço, dos pressupostos das autoras e da literatura da área em busca da compreensão do universo estudado, a partir do questionamento do status quo.

\section{Resultados e Discussão}

\section{Caracterização dos participantes}

Dentre os cinco psicólogos que aceitaram participar desta pesquisa, três atuavam em duas diferentes UBDS e dois em duas outras distintas UBS.

Todos os participantes eram do sexo feminino, com idade entre 39 e 53 anos, e atuavam há mais de 14 anos no serviço público. Neste período, duas participantes trabalharam em outros setores da Secretaria de Saúde que não na atenção primária à saúde. O tempo de atuação na saúde pública da maior parte das participantes extrapolou os 15 anos, o que significa que iniciaram suas atividades nesta área nos anos de 1990. Tal década foi marcada pelas transformações na área da saúde com a criação do SUS, baseada nos princípios da universalidade, equidade e integralidade na atenção, sob as diretrizes da descentralização dos serviços e da participação e controle social da comunidade. A Lei no 8.080 de 1990 foi concebida a partir do novo paradigma da saúde pública, fundamentada na compreensão do processo saúde-doença como produção social determinada pelas diferentes condições de vida, como descrito no artigo 3 :

A saúde tem como fatores determinantes e condicionantes, entre outros, a alimentação, a moradia, o saneamento básico, o meio ambiente, o trabalho, a renda, o transporte, o lazer e o acesso aos bens e serviços essenciais; os níveis de saúde da população expressam a organização social e econômica do País.

Segundo Alverga e Dimenstein (2005), a dimensão ampliada da compreensão do processo saúde-doença possibilitou a inserção de outros profissionais na área da saúde como os psicólogos, fonoaudiólogos, nutricionistas, fisioterapeutas e educadores físicos. Condição esta regulamentada em 1997 pela Resolução 218 do Conselho Nacional de Saúde (Brasil, 1997).

\section{Formação em saúde pública}

De acordo com os relatos das participantes, estas não receberam formação específica durante a graduação ou pósgraduação para atuação em saúde pública e atenção primária à saúde. As discussões sobre a ausência da formação do psicólogo na saúde pública não são recentes, estando presentes desde a década de 1970. Identificadas inicialmente nos trabalhos de Mello (1975) e Silva (1992), culminaram em extensa pesquisa em 2006, com o lançamento pelo Conselho Federal de Psicologia do ano da Psicologia e Saúde Pública.

Em 2005, se estabeleceu a primeira parceria entre o Ministério da Educação e o Ministério da Saúde por meio da Portaria Interministerial no 2.118 de 3 de dezembro de 2005 , para cooperação técnica na formação e desenvolvimento de recursos humanos na área da saúde. A ênfase na formação do profissional para o SUS é explicitada no Artigo $1^{\mathrm{o}}$ :

I - desenvolver projetos e programas que articulem as bases epistemológicas da saúde e da educação superior, visando à formação de recursos humanos em saúde coerente com o Sistema Único de Saúde (SUS), com as Diretrizes Curriculares Nacionais (DCN) e com o Sistema Nacional de Avaliação da Educação Superior (SINAES).

Entretanto, na Psicologia, esta discussão já havia sido intensificada e concretizada com a aprovação em 2004 das Novas Diretrizes Curriculares para o Ensino de Psicologia, como já discutido neste artigo. Na graduação em psicologia, temos um agravante, a formação em saúde pública tem sido pensada e realizada a partir de um olhar reducionista da Psicologia sobre o processo saúde-doença, restrito ao modelo individualista da Psicologia bem como do fenômeno psicológico, excluindo, muitas vezes, as outras dimensões deste processo. Tal concepção se traduz na ausência de conteúdos sobre a Saúde Pública e de seus determinantes sociais nas grades curriculares dos cursos.

Temas como a história da saúde pública no Brasil, as políticas públicas e o movimento da Reforma Sanitária são fundamentais para compreender como a Saúde Pública se configurou aos longos dos anos no país e de que forma os movimentos sociais participaram da construção do novo paradigma em saúde que se pretendeu operacionalizar por meio do SUS, sendo condição básica para que os profissionais da Psicologia compreendam não apenas seu papel na atenção primária à saúde como também a necessidade de interlocução com as outras áreas do conhecimento.

Outros temas essenciais são: historicidade dos modelos explicativos do processo saúde-doença, noções básicas de epidemiologia, o funcionamento do SUS em todas as suas dimensões (financiamento, gestão, assistência), modelos tecnoassistenciais em saúde, atenção primária à saúde, diagnóstico e planejamento em saúde. Ao focar as ações na atenção primária à saúde, é imprescindível que o psicólogo entenda os valores, princípios e formas de operacionalização dos mesmos no contexto brasileiro e de que maneira, a partir de sua profissão, pode atuar. Neste sentido, os conteúdos de diagnóstico e planejamento em saúde oferecem fundamentação teórica e prática para que as prioridades de um território em saúde sejam contempladas no serviço a ser oferecido. Desta forma, quebramos a autossuficiência do campo da Psicologia na definição do que deve ser a demanda, conforme discutiremos adiante. 
Temos uma prática profissional na atenção primária à saúde, até o momento, respaldada na saúde-doença mental que reproduz a visão de homem fragmentada, cartesiana e dicotômica. Para transformar esta visão tradicional, é necessário dialogar com a Saúde Pública durante a graduação, sem esta interlocução torna-se difícil o processo de inserção efetiva do psicólogo na saúde pública e sua compreensão de como suas práticas podem ser desenvolvidas neste contexto, para além da saúde mental.

Fica claro, por meio desses dados, o papel que os cursos de graduação desempenham na determinação dos modelos de atuação. Mudar a perspectiva de formação na graduação é de fundamental importância, mas não é suficiente, é necessário também olhar para os psicólogos que já estão nos serviços. Neste sentido, além dos programas de residência para aqueles que terminaram a graduação, sobre os quais já discorremos, outra iniciativa do Governo Federal é a criação dos polos de Educação Permanente, os quais têm estabelecido como prioridade a formação para a atenção primária à saúde por meio da Estratégia Saúde da Família (ESF), em parceria com Universidades e Escolas Técnicas. No entanto, como o psicólogo não faz parte da equipe mínima da ESF, geralmente, ele não participa dos cursos oferecidos e muitas vezes não demonstra interesse em participar, dificultando a discussão sobre as mudanças necessárias nesta prática.

\section{Práticas psicológicas na atenção primária à saúde}

Segundo relato das participantes, as práticas no contexto da atenção primária à saúde foram definidas em reuniões realizadas entre os profissionais da área e a coordenação do Programa de Saúde Mental do município. Algumas dimensões foram priorizadas pelos profissionais para o estabelecimento das diretrizes do Serviço de Psicologia, como: faixa etária, tipo de demanda, modalidade de intervenção e nível de atenção em saúde.

Em relação à faixa etária, os profissionais definiram que atenderiam apenas crianças e adolescentes (zero aos dezessete anos). Adultos seriam encaminhados para outros serviços oferecidos pela rede municipal ou estadual de saúde. Vale ressaltar que estes últimos eram ofertados apenas na região central da cidade, dificultando o acesso da população. Tal forma de organização contraria a perspectiva da acessibilidade e da atenção primária à saúde como porta de entrada para o serviço de saúde, devido à proximidade geográfica que deve ser mantida com a população (Starfield, 2002).

No que concerne ao tipo de demanda, decidiu-se pelo atendimento de problemas emocionais e comportamentais, o que nos sugere a visão ainda tradicional sobre o processo saúde-doença bem como a ênfase na dimensão psicológica, representando uma abordagem fragmentada do ser humano ao reduzi-lo a tal dimensão ou à doença. Ao restringir o atendimento aos "problemas", subtraíram-se as potencialidades individuais e coletivas do contexto em que o profissional trabalha, os recursos, as redes de apoio, as contribuições que a própria Psicologia Social e Comunitária podem oferecer para uma prática psicológica mais crítica, contextualizada social e culturalmente. Esta posição nos aponta para uma incompreensão do que seja necessidade em saúde e demanda, visto que o foco das ações está sobre os profissionais e não sobre o sujeito (individual ou coletivo). As necessidades da população não se constituem em demandas a partir do encontro entre sujeitos, serviços e profissionais, como sugere Camargo Jr. (2005), mas no enquadramento dos "problemas emocionais ou comportamentais" apresentados pelos sujeitos às necessidades do profissional. Dessa forma, enfrentamos uma organização de serviço autocentrada que exclui características imprescindíveis ao fazer psicológico, como o caráter relacional, dialógico e processual, não apenas em relação ao contexto do nível de atenção em que trabalha e aos usuários, mas de toda a rede de assistência e suas interlocuções que configuram a intersetorialidade e a integralidade das ações.

A atuação majoritária foi estabelecida no nível secundário de atenção à saúde, com o predomínio de práticas tradicionais baseadas no modelo biomédico, independente da modalidade de atendimento (individual, em grupo e orientação de pais). Segundo os relatos das participantes, a decisão por priorizar o nível secundário foi tomada a partir da sugestão das mesmas, devido ao perfil e número reduzido de profissionais que atuavam naquele momento. No entanto, faz-se importante questionarmos por que a resposta das profissionais e da coordenação de saúde mental foi adotar tal solução caracterizada pela passividade e alienação frente a uma realidade que clama por um compromisso político, ético e social? Ao estabelecerem tais diretrizes, os profissionais amputaram as oportunidades de ousar, criar, construir outros modos de fazer psicologia na atenção primária em nome da segurança, do conhecido, da manutenção do status quo e da ilusória identidade profissional que se sustenta no modelo clínico tradicional, conforme relato transcrito abaixo:

Eu atendo clinicamente aqui e atendo clinicamente
no meu consultório. (...) É o mesmo nesse sentido.
Agora, se você for contar que você tá numa insti-
tuição e que você pode ser solicitada pra n coisas,
assim, muitas vezes eu tive que dizer: "Não, eu não
posso". Porque nós somos chamadas pra partici-
par de grupo de hipertensos, grupo de diabéticos,
grupo de não sei o que, você fala: "Não dá, eu não
tenho perna, eu tenho uma agenda pra cumprir",
se eu for participar desse monte de grupo eu não
vou atender clinicamente ninguém (ri), entendeu?
(Participante 5)

Observamos, no relato acima, que a prática é a mesma no consultório particular e na instituição. O que difere é o tipo de solicitação e a sobrecarga de trabalho em função de outros atendimentos que extrapolam o clínico. É evidente que nos deparamos com um quadro aquém da necessidade do município, o qual contava com aproximadamente $600 \mathrm{mil}$ habitantes em 2007 (Fundação Sistema Estadual de Análise de Dados, 2007) e apenas nove psicólogos na atenção primária à saúde. Entretanto, esta situação se mantém há anos, o 
que sugere que os descontentamentos dos profissionais não foram transformados em propostas e reivindicações fortes o suficiente para mudar tal situação.

Mesmo com a informação de que as participantes adotavam apenas práticas do nível secundário, questionamos se realizavam alguma atividade que poderiam considerar do nível de atenção primária. Estas relataram práticas esporádicas e limitadas a solicitações de outros profissionais em eventos específicos, como transcrito abaixo:

Acontece mais ou menos assim em épocas especificas, vamos supor, tem alguma, como é que fala assim, alguma semana de alguma coisa, então vamo supor "Semana da Hipertensão", então às vezes a gente é convidado pra participar com alguma coisa no sentido, ou de uma palestra, né, ou pra fazer algum grupo. Então não é uma coisa que também é assim, é sistematizada, funciona por convites. (Participante 4)

Outra participante especifica o número de procedimentos, de acordo com a carga horária do profissional:

Que ficou padronizado: fazer nove atendimentos individuais por semana, dois casos novos, duas triagens, por semana, isso pra quem faz 20 horas, e acho que quatro grupos, três ou quatro grupos de quatro pessoas no mínimo, tá? Fechamos o pacote. (Participante 5)

A ideia de "funcionar por convites" ou "fechar um pacote" explicitada nos relatos acima nos remete à rigidez no enfrentamento do cotidiano dos serviços que parece se organizar independente do movimento de vida das pessoas que buscam pelo serviço de saúde. Os termos por nós sublinhados nos chamam a atenção para a posição adotada por tais profissionais, cômoda ao oferecer um pacote à população que se justifica, fundamentalmente, pelo número de horas de trabalho e pelo que se "pode" oferecer em termos de práticas.

Esta maneira de organização do serviço implica em um descompasso com os princípios de resposta coordenada às necessidades da população, com a garantia à universalização do acesso e com a equidade no atendimento. Um serviço não deve ser organizado em função estrita dos desejos dos profissionais, mas no encontro entre as necessidades de saúde da população que busca pelo serviço de saúde, o que este prevê oferecer a partir de diretrizes estabelecidas e o que o profissional naquele contexto pode oferecer.

Segundo Camargo Jr. (2005), os usuários procuram os serviços de saúde em busca de soluções para seus problemas. As respostas geralmente não correspondem ao esperado pelo usuário, pois se baseiam em categorias definidas institucionalmente. Esta formatação dificulta a escuta qualificada do profissional para com as necessidades do usuário. Esta condição é imprescindível para que a inversão na lógica do cuidado aconteça de maneira efetiva. Os critérios utilizados para definição desse "pacote" não foram explicitados pela participante, no entanto, fica claro que as necessidades e demandas da população não se constituíram em foco desta discussão. Desta forma, torna-se difícil pensar em um serviço que responda aos desejos da população e, principalmente, que se estruture nos pilares da atenção primária à saúde.

É evidente que os serviços devem oferecer opções para o usuário, fundamentadas na leitura sobre a dinâmica da população que reside num determinado território. No entanto, o que estes dados nos sugerem é que não há espaço para a opção, apenas para a imposição de serviços predefinidos, de acordo com as características do profissional. Uma prescrição que, nas palavras de Freire (1987), significa imposição de uma opção, visto que existem outras possibilidades, porém sequer são apresentadas.

Sendo assim, é interessante nos questionar sobre como os profissionais da Psicologia lidam com a subjetividade dos usuários dos serviços? Há uma modelagem desta subjetividade para que se encaixe em um modelo seguro de atuação? Defrontamo-nos com outra questão, o predomínio da utilização de técnicas psicoterápicas dentro desse pacote de serviços. De acordo com todas as participantes, predominam os atendimentos psicoterápicos que nos remetem à reflexão sobre qual a posição que tais técnicas têm ocupado nas ações da Psicologia na atenção primária à saúde. $\mathrm{O}$ relato das participantes evidencia que outras possibilidades de atuação são praticamente ausentes, de tal forma que é possível refletir, a partir de Dimenstein (1998), que em muitos casos as psicoterapias tradicionais são tomadas como o único instrumento de trabalho do psicólogo e como portadoras de um valor intrínseco, independente de onde e com quem são utilizadas (Contini, 2001; Dimenstein, 2000, 2001; Spink, 2003). Concordamos com Silva (1992) e Lo Bianco (1989), ao apontarem que o maior problema não é a importação da teoria em si, mas a crença em sua aplicação de maneira generalizada, rígida e irrestrita dos procedimentos clínicos a todo e qualquer grupo sociocultural.

Pensar no papel do psicólogo na atenção primária à saúde é também pensar na reconstrução de sua prática clínica nesse contexto. O trabalho clínico é constituinte da atuação de qualquer profissional de saúde, desde que realizado de maneira ampliada, isto é, não reduzido à reprodução do modelo tradicional. De acordo com Campos (2000), a clínica ampliada é a redefinição do objeto, do objetivo e dos meios de trabalho da assistência individual, familiar ou a grupos. Constrói-se um objeto para o trabalho da clínica que não se restringe ao nível individual, mas aos grupos (a família e outros coletivos, uma classe, um agrupamento institucional).

Trata-se, portanto, da ampliação do olhar que resulta em considerar elementos orgânicos (biológicos), subjetivos e sociais do processo saúde-doença, ao modificar os meios de trabalho, ou seja, a escuta, a entrevista, a intervenção terapêutica, descentrando-as do uso quase que exclusivo de medicamentos ou de procedimentos técnicos engessados, o que possibilita fazer uso com maior frequência de técnicas de prevenção, de educação em saúde e de reconstrução da 
subjetividade. É a ausência desse referencial que questionamos nas práticas desenvolvidas pelo serviço estudado e não o caráter clínico propriamente dito ou sua substituição por outros modelos, uma vez que se assim o fizéssemos sobreporíamos o coletivo/social sobre o individual/subjetivo.

No trabalho de Barbosa e Mendes (2005) sobre as concepções de promoção da saúde dos psicólogos que trabalhavam no serviço público de uma cidade do interior paulista, encontramos resultados que compartilham da posição acima discutida. Os profissionais apresentaram percepções diferenciadas, ao relatarem que consideraram o trabalho intersetorial condição fundamental para efetivação de sua prática, no contexto da promoção da saúde. Demonstraram, assim, uma concepção do processo saúde-doença que extrapola a dimensão psicológica.

Outro aspecto que gostaríamos de discutir é a percepção das entrevistadas sobre o papel do psicólogo no nível da atenção primária à saúde. Ao serem questionadas sobre tal função, todas apontaram a ação em escolas e creches, por meio de observação e orientação, como sendo esse papel, mas é evidente a dificuldade em sistematizar essa atuação, de tal forma que parece existir, entre essas profissionais, pouco conhecimento sobre qual o papel do psicólogo nesse nível de atenção. As falas das participantes 2 e 5 exemplificam essa colocação.

Então, acho que com os professores dá pra trabalhar muito, na escola, com o coordenador, com a própria diretora dá pra trabalhar bastante, é... com criança, às vezes algumas crianças que realmente têm alguns problemas maiores de comportamento, acho que antes de estar encaminhando pra uma terapia, pra um trabalho secundário, acho que daria pra tá tentando fazer alguma coisa dentro da própria escola, né? (Participante 2)

Olha, na minha opinião, deveria existir um psicólogo em cada escola, um psicólogo em cada creche, em cada núcleo, isso seria uma atenção primária, tá?(...) Mas, o que eu penso de primário acho que seria isso, né? Escola, creche, um trabalho no posto de acolhimento, não que eu pense que precise largar o atendimento semanal, e ela vem, vem pra ser avaliada, né?(...) Eu acho que é isso, não sei, não penso, eu não sei pensar agora outra, outra coisa. (Participante 5)

Em consequência disso, há o reconhecimento da importância desse trabalho, mas a ser desenvolvido por outros profissionais, transferindo assim o seu compromisso com o lugar que ocupa, como relatou a participante 5 .

E eu acho que é uma questão muito importante, eu acho que é preciso, mas não a gente fazer, eu acho que tem que ser separado, precisa do secundário também, precisa do atendimento clinico, né?(...) Então, eu acho que poderia existir um trabalho primário, não sei esquematizar muito de que jeito, mas deveria, porque senão fica essa, vamos dizer, pressão, pra gente fazer tudo, né? E não dá conta. A gente tem lista de espera, né? Não dá conta de fazer tudo. (Participante 5)

É possível notar também uma certa confusão sobre qual o papel do psicólogo em uma unidade de saúde. Em alguns momentos, tal prática é apontada como igual ao desenvolvido no consultório, por representar uma prática clínica; em outros, é considerada diferente por envolver um trabalho em equipe e estar direcionada a outro tipo de população, como evidencia a seguinte fala:

Mas, mesmo assim, é uma unidade de saúde, então não é a mesma coisa de um atendimento que você tá indo no consultório. Agora, de resto, tirando algumas coisas mais especificas, eu acho que são procedimentos normais dentro da sala, né? $O$ atendimento, a maneira de orientar a mãe, eu acho que são atendimentos, pelo que eu converso também com a outra psicóloga que tem consultório, né? Eu acho que, basicamente, são os mesmos procedimentos. (Participante 2)

A respeito do papel do psicólogo no nível da atenção primária à saúde, concordamos com Spink (2003) que sugere que a atuação do psicólogo nas instituições de saúde deve se fundamentar em uma prática ampliada, principalmente, em relação ao referencial de trabalho utilizado e exercido, e abrange duas principais questões: contextualização da intervenção e reconhecimento da alteridade. As intervenções do psicólogo em uma instituição de saúde devem levar em conta a interface da cultura e do social, no processo de construção da identidade e da inserção da pessoa na vida. Trata-se de uma atuação centrada em uma perspectiva coletiva de comprometimento com os direitos sociais e com a cidadania. Rompe, portanto, com os enfoques mais tradicionais centrados no indivíduo. Focaliza a prevenção da doença e a promoção da saúde e incentiva os atores sociais envolvidos para a geração de propostas de transformação do ambiente em que vivem, acarretando em um processo de transformação crítica e democrática que potencializa e fortalece a qualidade de vida.

\section{Considerações finais}

Fica evidente, a partir dos dados analisados, que as propostas de mudanças discutidas e incorporadas à legislação, no decorrer das duas últimas décadas, ainda não encontram reflexo na atuação dentro do serviço psicológico oferecido nas Unidades Básicas e Distritais de Saúde, no município estudado. É certo, também, que tal fato advém da combinação de múltiplos fatores. Não é possível ignorar a prevalência da identificação dos profissionais com a prática clínica, a qual parece corresponder à imagem profissional que possuem da 
Psicologia. Muitos estudos já apontaram para o predomínio do modelo clínico, tanto no ensino como nas práticas em Psicologia, no entanto, acreditamos que a questão não está em realizar ou não a prática clínica, mas sim em resumi-la ao atendimento clínico tradicional, descontextualizado e acrítico. Consideramos que todo profissional de saúde que cuida de pessoas realiza clínica, havendo, portanto, várias modalidades de clínica, as quais no contexto da atenção primária à saúde devem ser reformuladas, ampliando seu objeto de intervenção e a sua maneira de olhar a realidade na qual se insere, constituindo, dessa forma, uma prática clínica ampliada.

Aspectos políticos como falta de verbas, ausência de concursos, escassez de profissionais na rede, reduzido interesse político e de valorização do trabalho também constituem um entrave para o estabelecimento de práticas que sejam mais coerentes com as necessidades da população atendida. Para Dimenstein (1998), a política de saúde presente atualmente nas instituições de saúde em todo o Brasil está muito mais preocupada com a produção do que com a qualidade dos atendimentos, de tal forma que tem levado o psicólogo, frequentemente, a um desencantamento com seu trabalho.

No entanto, não se pode restringir a reflexão ao tipo de demanda (que se diferencia daquela da clínica privada) e às dificuldades atribuídas à clientela de baixa renda (usuária do setor público) nem aos problemas relacionados com a estrutura e organização dos serviços, pois, apesar de serem elementos importantes, não esgotam a questão. Os aportes teóricos e práticos que fundamentam os modelos de atuação são importantes questões a serem consideradas para repensar a formação dos profissionais, de maneira a prepará-los para o exercício da Psicologia, no contexto da saúde pública e da atenção primária à saúde.

Nesse sentido, começamos a avançar por meio das propostas de reestruturação curricular que não se esgotam na operacionalização das Novas Diretrizes Curriculares, as quais promovem a discussão sobre a formação para o SUS. Outras dimensões devem ser incorporadas neste processo, como: a efetivação da educação permanente como estratégia de reorganização dos serviços de psicologia e a reestruturação das diretrizes que regulamentam os concursos públicos, as quais não relevam o perfil profissional desejado para atuação na saúde pública, priorizando provas com temas ligados à prática clínica tradicional.

Por fim, é importante apontar para a previsível dificuldade existente entre os profissionais em estabelecer novas práticas de atuação, uma vez que não encontram nessas a mesma segurança que possuem ao realizarem aquelas conhecidas e dominadas por eles, desde o início de sua formação. Nesse sentido, a busca de novas alternativas exige, por outro lado, o correspondente desenvolvimento de novos suportes teórico-metodológicos, implicando alterações substantivas na formação do psicólogo, de forma a possibilitar a instrumentalização desses profissionais diante dos desafios da prática.

\section{Referências}

Alverga, A. R., \& Dimenstein, M. (2005). Salud mental en la atención básica: Construyendo la integralidad en el Sistema Unico de Salud en Brasil. Revista Altenativas en Psicologia, 10(12), 67-77.

Barbosa, C. F., \& Mendes, I. J. M. (2005). Concepção de promoção da saúde de psicólogos no serviço público. Paideia (Ribeirão Preto), 15, 269-276.

Bogdan, R., \& Biklen, S. (1994). Investigação qualitativa em educação: Uma introdução à teoria e aos métodos. Porto, Portugal: Porto Editora.

Brasil. Ministério da Saúde. Conselho Nacional da Saúde. (1997, 6 de março). Resolução 218. Brasília, DF. Recuperado em 01 maio 2009, de http://www.datasus.gov.br/ conselho/resol97/res21897.htm

Brasil. Ministério da Saúde. Conselho Nacional de Saúde. (2000). Normas para pesquisa envolvendo seres humanos (Cadernos Técnicos). Brasília, DF: Ministério da Saúde.

Camargo Jr., K. R. (2005). Das necessidades de saúde à demanda socialmente constituída. In R. Pinheiro \& R. A. Mattos (Orgs.), Construção social da demanda: Direito à saúde, trabalho em equipe, participação e espaços públicos (pp. 91-101). Rio de Janeiro: IMS-UERJ.

Campos, G. W. S. (2000). Um método para análise e cogestão de coletivos. São Paulo: Hucitec.

Carta de Ottawa. (1986). I Conferência internacional de promoção de saúde. Ottawa, Canadá. Recuperado em 01 maio 2009, de http://www.opas.org.br/promocao/ uploadArq/Ottawa.pdf

Clemente, A., Matos, D. R., Grejanin, D. K. M., Santos, H. E., Quevedo, M. P., \& Massa, P. A. (2008). Residência multiprofissional em saúde da família e a formação do psicólogo para a atuação na atenção básica. Saúde $e$ Sociedade, 17(1), 176-184.

Conselho Federal de Psicologia. (1988). Quem é o psicólogo brasileiro. São Paulo: Edicon.

Conselho Nacional de Educação. Câmara de Educação Superior. (2004, 19 de fevereiro). Diretrizes curriculares nacionais para os cursos de graduação em psicologia: Parecer CNE/CES no. 62/2004. Brasília, DF. Recuperado em 20 janeiro 2006, de http://www.abepsi.org.br/web/ diretrizes.aspx\#

Contini, M. L. J. (2001). O psicólogo e a promoção de saúde na educação. São Paulo: Casa do Psicólogo.

Crossley, M. C. (2000). Rethinking health psychology. Philadelphia, PA: Open University Press.

Declaração de Alma-Ata. (1978). I Conferência internacional sobre cuidados primários à saúde. Alma-Ata: URSS. Recuperado em 01 maio 2009, de http://www.opas.org. br/coletiva/uploadArq/Alma-Ata.pdf

Delgado, J. M., \& Gutierrez, J. (1995). Métodos y técnicas cualitativas de investigación em Ciencias Sociales. Madrid, Espanha: Sinteses. 
Dimenstein, M. D. B. (1998). O psicólogo nas unidades básicas de saúde: Desafios para a formação e atuação profissionais. Estudos de Psicologia, 3, 53-81.

Dimenstein, M. D. B. (2000). A cultura profissional do psicólogo e o ideário individualista: Implicações para a prática no campo da assistência pública à saúde. Estudos de Psicologia, 5, 95-121.

Dimenstein, M. D. B. (2001). O psicólogo e o compromisso social no contexto da saúde coletiva. Psicologia em Estudo, 6(2), 57-63.

Dimenstein, M. D. B. (2003). Los (des)caminos de la formación profesional del psicologo en Brasil para su actuación en la salud publica. Revista Panamericana de Salud Pública, 13, 341-345.

Dimenstein, M. D. B. (2006). A prática dos psicólogos no Sistema Único de Saúde/SUS. Fórum Nacional de Psicologia e Saúde Pública, 1, 8-16. Brasília, DF: Conselho Federal de Psicologia.

Freire, P. (1987). Pedagogia do oprimido (15a ed.). Rio de Janeiro: Paz e Terra.

Fundação Sistema Estadual de Análise de Dados. (2007). Perfil municipal de Ribeirão Preto. São Paulo: Autor. Recuperado em 22 outubro 2007, de http://www.seade. gov.br/produtos/perfil/perfil.php

Lei No. 8.080, de 19 de setembro de 1990. (1990, 19 de setembro). Dispõe sobre as condições de promoção, proteção e recuperação da saúde, a organização e o funcionamento dos serviços correspondentes e dá outras providências. Recuperado em 01 maio 2009, de https://www.planalto. gov.br/ccivil_03/leis/18080.htm

Lo Bianco, A. C. (1989). Questões para a teoria psicanalítica na sociedade brasileira. In J. Birman (Org.), Freud 50 anos depois (pp. 241-251). Rio de Janeiro: Relume-Dumará.

Lodi, J. B. (1992). A entrevista: Teoria e prática. São Paulo: Pioneira.

Luz, M. T. (1994). As conferências nacionais de saúde e as políticas de saúde na década de 80 . In R. Guimarães \& R. A. W. Tavares (Orgs.), Saúde e sociedade no Brasil: Anos 80 (pp.131-152). Rio de Janeiro: Relume-Dumará.

Mello, S. L. (1975). Psicologia e profissão em São Paulo. São Paulo: Ática.

Mendes, E. V. (2006). Um novo paradigma sanitário: A produção social da saúde. In E. V. Mendes, Uma agenda para a saúde (2a. ed., pp. 233-300). São Paulo: Hucitec.

Minayo, M. C. S. (1994). O desafio do conhecimento: Pesquisa qualitativa em saúde (3a ed.). Rio de Janeiro: Abrasco.

Oliveira, I. F., Dantas, C. M. B., Costa, A. L. F., Silva, F. L., Alverga, A. R., Carvalho, D. B. e cols. (2004). O psicólogo nas unidades básicas de saúde: Formação acadêmica e prática profissional. Interações, 9(17), 71-89.

Oliveira, I. F., Dantas, C. M. B., Costa, A. L. F., Gadelha, T. M. S., Ribeiro, E. M. P. C., \& Yamamoto, O. H. (2005). A psicologia, o Sistema Único de Saúde e o Sistema de Informações Ambulatoriais: Inovações, propostas e desvirtuamentos. Interação em Psicologia, 9, 273-283.
Portaria Interministerial No. 2.118, de 3 de novembro de 2005. (2005, 3 de dezembro). Institui parceria entre o Ministério da Educação e o Ministério da Saúde para cooperação técnica na formação e desenvolvimento de recursos humanos na área da saúde. Recuperado em 01 maio 2009, de http://portal.saude.gov.br/portal/arquivos/pdf/B\%20 2118\%20INSTITUIR\%20PARCERIA \%20ENTRE\%20 O\%20\%20MEC\%20e\%20o\%20\%20MS\%20REF.pdf

Ronzani, T. M., \& Rodrigues, M. C. (2006). O psicólogo na atenção primária à saúde: Contribuições, desafios e redirecionamentos. Psicologia: Ciência e Profissão, 26, 132-143.

Silva, R. C. (1992). A formação em psicologia para o trabalho na saúde pública. In F. C. B. Campos (Org.), Psicologia e saúde: Repensando práticas (pp. 25-40). São Paulo: Hucitec.

Simon, C. P. (2003). Promoção de saúde na comunidade: Análise de relatos de experiências na literatura sob a perspectiva da psicologia crítica. Tese de doutorado nãopublicada, Universidade de São Paulo, Ribeirão Preto, SP.

Soares, T. C. (2005). A vida é mais forte do que as teorias: O psicólogo nos serviços de atenção primária à saúde. Psicologia: Ciência e Profissão, 25, 590-601.

Spink, M. J. P. (2003). A formação do psicólogo para atuação em instituições de saúde. In M. J. P Spink, Psicologia social e saúde: Práticas, saberes e sentidos (pp. 132-140). Petrópolis, RJ: Vozes.

Spink, M. J. P. (2006). A Psicologia em diálogo com o SUS: Prática profissional e produção acadêmica. Relatório Final Projeto Coletivo de Cooperação Técnica da Associação Brasileira de Ensino de Psicologia: Mudança na Formação em Psicologia e Pesquisa e Sistematização de Experiências. Recuperado em 16 janeiro 2007, de http:// www.abepsi.org.br/web/Relatorio_pesquisa_ABEP.pdf

Starfield, B. (2002). Atenção primária: Equilíbrio entre necessidades de saúde, serviços e tecnologia. Brasília, DF: UNESCO.

Valles, M. S. (1997). Tecnicas cualitativas de investigacion social: Reflexión metodologica y practica profesional. Madri, Espanha: Editorial Síntesis.

Juliane Fernandes Simões de Mattos Andrade é Residente em Saúde da Família e Comunidade pelo Programa de Residência Multiprofissional em Saúde da Família e Comunidade do Departamento de Medicina da Universidade Federal de São Carlos, bolsista Ministério da Saúde.

Cristiane Paulin Simon é Professora Adjunta do Departamento de Medicina Social da Universidade Federal do Triângulo Mineiro. 